\title{
Zoning Strategies for Urban Land Use Planning
}

\author{
Pratibha Bhadhane, R. K. Jain, Deepa A. Joshi, Radhika Menon
}

\begin{abstract}
The principal instruments of urban planning are assessment of existing land, zoning strategies, consideration of futuristic developments and other necessary infrastructure. Along with the fundamental planning principals, adoption of modern tools and techniques is necessary to accomplish sustainable growth at faster rate in Indian scenario. In this paper, the urban land use planning/zoning for Maharashtra and Japan has been discussed in detail. Through this critical comparative study, practices, which are adaptable from Japan model, are recommended in order to develop a multi-criteria framework for advance planning for Maharashtra.
\end{abstract}

Keywords : Urban Planning, Land Use Planning, Zoning, Maharashtra, Japan.

\section{INTRODUCTION}

Planning the development of any urban/rural area is a key for its sustainable growth. In concern with the physical planning, use of land, provision of amenities and utilities hold prime importance. A Development Plan is a comprehensive document outlining the vision and development strategy for future development of the city, prepared in consultation with a wide range of stakeholders to identify the thrust areas to be addressed on priority basis. It is projected that urban population in India will increase from 288 million in 2011 to approximately 475 million in 2031and 820 million by 2051 (Census of India 2011)[1]. Kiranmayi Raparthi (2014) reveals that cities in India do not implement the multi-criteria framework for smart development and the use of development strategies differs among highly populated metropolitan cities versus less-populated cities[2]. Researchers have evaluated the effective factors for the function and positions of the Article Five Commission (AFC) toward Sustainable Urban Development (SUD) of Tehran[3]. An optimal logistics nodes assessment framework based on the analytic hierarchy process (AHP) and the fuzzy synthetic evaluation method, on the basis of extensive field study in Yanting has been presented [4]. Fengjun Yin et. al studied to improve the level of service of transit and implement transit priority in new towns, the average spacing of the arterial road network is recommended, aiming at meeting the requirement

Revised Manuscript Received on February 05, 2020.

* Correspondence Author

R.K.Jain*, Principal, RSCOE, Tathwade, Pune, India. Email: jainrb20@gmail.com

Pratibha Bhadhane, PhD Research Scholar Civil Engineering, Dr. D. Y Patil Institute of Technology, Pimpri, Pune, India. Email: rashima@gmail.com

Deepa A. Joshi, Professor in Civil Engineering, Dr. D. Y. Patil Institute of Technology, Pimpri, Pune, India. Email: joshi.deepa13@hgmail.com

Radhika Menon, Professor, Dr. D. Y. Patil Institute of Technology, Pimpri, Pune, India. Email: radhika.tharoor@gmail.com

(C) The Authors. Published by Blue Eyes Intelligence Engineering and Sciences Publication (BEIESP). This is an open access article under the CC BY-NC-ND license (http://creativecommons.org/licenses/by-nc-nd/4.0/) of bus stop coverage rate [5]. Studies on the characteristic of village and town construction standard system requirements in China are also available [6].

Yikun Su, et.al (2013) focused on problems of a shortage of rural public facilities and their low quality, as well as an imbalanced regional allocation, poor dynamic adaptability to meet demands, and an excess supply and partial short supply existing side by side. Aiming at the problems above, it proposes supporting standards and an innovative configuration mode as some countermeasures [7]. Deyong Yu,et.al (2011), aimed at the application of ecological principles to develop an integrated urban land-use planning with optimization of ecosystem of urban area, and a case study of Panyu has been discussed in detail [8].

Few researchers focused on fixing the traffic problems in the developmental process of small towns, the planning method of a small-town traffic system is imminently asked for studying and improvement [9]. M.S. Mir et al. [2010] developed a methodology for the development of a space development (SD) model for a developing region. The proposed methodology is tested by applying it to simulate the $\mathrm{SD}$ in the Mumbai Metropolitan Region (MMR) in India [10].

There is a need to review the major aspects of urban planning in India. It makes a case for an integrated approach recognizing the interplay of factors which have a bearing on the urban condition for better living as well as better environment for economic growth, which should be inclusive and sustainable. Therefore, extensive understanding is required for urban planners on the impact of zoning regulations on city development, thereby developing a multi criteria framework for advance planning.

\section{METHODOLOGY}

Through the in-depth study of global and Indian best practices for Urban Land use, the zoning strategies can be proposed. In the present study, Japan has been considered for the same. Zoning strategies of Maharashtra and Japan are studied in detail. The comparative analysis has been prepared. On the basic of this study, carried out at Japan, under the study tour program of Government of Maharashtra, few important recommendations for developing a multi criteria framework for advance planning of Maharashtra has been proposed. The compilation of this extensive work has been presented in this paper.

\section{PLANNING SCENARIO IN MAHARASHTRA AND JAPAN}

Adoption of advanced techniques and tools is necessary in India for achieving sustainable urban development. The detailed study and comparison with advanced countries is needed for decision making. 


\section{Zoning Strategies for Urban Land Use Planning}

The planning scenario in Maharashra and Japan is discussed here.

\section{A. Planning scenario in Maharashtra}

In Maharashtra, Development Plans is prepared as per regulations mentioned in the Maharashtra Regional and Town Planning Act, 1966. Section 22 of MR\&TP Act, 1966 provides the contents of Development Plan as following -

- Proposals assigning land usage for various categories as residential, commercial, industrial, agricultural, and recreational.

- Proposals for allocation of land for various public purposes like, educational institutes, health institutions, markets, social and cultural institutions,

- Proposals of open spaces, playground etc.

- Proposals for transportation and communication

- Proposals for public utilities such as water supply, drainage, sewerage, electricity supply etc.

- Proposals for designation of sites for industrial estates service industries etc.

- Proposals of preservation and conservation of natural scenery, heritage structures and precinct.

"Planning Standards" are adopted as a tool to accomplish well planned, balanced, user friendly, inclusive, sustainable and futuristic development of city. Normally Planning standards are based on the ration of Land Area /population of the city. Till today, planning standards of 1979 are adopted for preparation of Development Plans. 1979 planning standards are mainly prepared for recreational amenity such as Garden and Playgrounds, educational amenity such as Primary school, High school and play grounds, Medical amenity such as Dispensaries, maternity Homes and Hospitals, commercial amenity such as Shopping Center, Vegetable Market, Fish and Mutton Markets, Cultural amenity such as Community Center, Library and Gymnasium etc. and for Parking amenity. City level amenities are also introduced such as Sewage Treatment Plant, Water Works, Solid Waste Management, Fire Brigade Station, Hospital, Stadium, Auditorium, Municipal Market, Hawker's zone, Cremation Ground / Burial Ground, Slaughter House, Truck Terminus, Bus Stand etc. But in today's contest, taking into consideration the land/population ratio, it is very difficult to prepare Development Plan as per 1979 Planning Standards / guidelines. It is the time now to adopt innovative ideas / technique for preparation of Development Plan of new cities or newly formed Nagar Parishads / Nagar Panchayats in Maharashtra.

\section{B. Planning Scenario in Japan}

In Japan, City Plans are prepared, as per regulations mentioned in the City Planning Act. City Plans are based on the Fundamental principle, that healthy, cultural urban lifestyles and functional urban activities should be secured while maintaining a healthy balance with the agriculture, forestry and fishery industries, and that reasonable land use under due regulations should be promoted for this reason.

In Japan, City Plans are prepared, as per regulations mentioned in the City Planning Act. Focus of city planning is on health and hygiene, life style based on urban culture and ensuring proper balance with ecosystem. Appropriate utilization of land should be considered for the said purpose.

In concern with providing various facilities, provisions for residential townships, Government and private offices, educational institutions, cultural centers, hospitals, open spaces, public utility spaces and road networks.

\section{LAND USE PLANNING IN MAHARASHTRA AND JAPAN}

Well organized planning and ethical aspects is an essential component in any urban planning. This consists of systematic evaluation of available land, assessment of various alternate options for land use and economic and social conditions of the area.

Land use planning in Maharashtra and Japan is discussed in detail, for understanding the zoning strategies.

\section{A. Land Use Planning in Maharashtra}

In Maharashtra as per the provisions of the Maharashtra Regional and Town Planning Act, 1966, in the Development Plan, land use planning / zoning is mostly done for Residential, Commercial, Recreational (Garden, Play Ground), Industrial, public-semi public, public utilityTraffic and Transportation, Agricultural, Water Bodies, and Forest Land. Residential zone planning should be capable of catering for projected population, by taking into consideration, the major parameters as cost effectiveness and zoning compactness. Major factors to be considered for planning of residential zone are development pattern of the area, proximity to major road connects topography of the area, important activity centers and sequential geographical continuity with the current or with proposed plan.

In It is expected that a comprehensive road network will improve the connectivity and facilitate the Transportation and hence it is considered in the planning. Development Plan also aims at creating an environment to enable the resident to enjoy the desired standards of living conditions. Therefore, creation of necessary amenities is an integral part of the development plan.

\section{B. Land Use Planning in Japan}

Considering the provisions of City Planning Law, based on the local needs, the Government prepares the various strategies. Planning for land usage depends on various parameters, and the regulations are made by giving due weight-age to each parameter and their appropriate blend.

Area Division System: In order to develop efficient infrastructure, to achieve sustainable urban development, for giving justice to public funds, 'Area Division System' technique is adopted. This consists of dividing the area into two categories, mainly for Promotion and Control of Urbanization.

Zones for Urban Land use: The Land use strategy in Japan, envelopes three general categories, Residential, Commercial and Industrial, divided into twelve zones. Regulations for the construction of building in every zone have been specified by considering futuristic development.

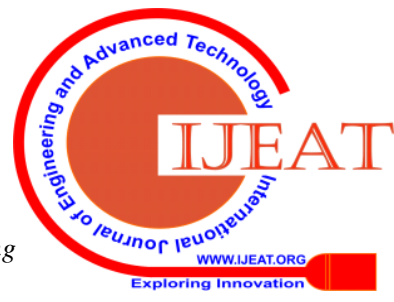


These zones are discussed here in brief to understand the strategy of zoning in Japan, also summarized by Ryosuke Ando et al. (2018) [11].

1. Category I: Exclusively low-rise Residential Zone This zone is designated for low rise residential buildings. The permitted buildings include residential buildings which are also used as small shops or offices and elementary /junior high school buildings.

2. Category II: Exclusively low-rise Residential Zone This zone is mainly designated for low rise residential buildings. In addition to elementary /junior high school buildings, certain types of shop buildings with a floor area up to $150 \mathrm{~m}^{2}$ are permitted.

3. Category I: Mid/high-rise oriented Residential Zone This zone is designated for medium to high residential buildings. In addition to hospital and university buildings certain types of shop buildings include residential buildings with a floor area of up to $500 \mathrm{~m}^{2}$ are permitted.

4. Category II: Mid/high-rise oriented Residential Zone This zone is mainly designated for medium to high residential buildings. In addition to hospital and university buildings permitted buildings include certain shop and office buildings with a floor area of up to $1500 \mathrm{~m} 2$ To provide conveniences for the local community.

5. Category I : Residential Zone: This zone is designated to protect the residential environment. The permitted buildings include shops, offices and hotel buildings with a floor area of up to 3000 sq.mt.

6. Category II : Residential Zone - This zone is designated to mainly protect the residential environment. The permitted buildings include shops, offices and hotel buildings as well as buildings with karaoke box.

7. Quasi Residential Zone: This zone is designated to allow the introduction of vehicle related facilities along roads while protecting residential environment in harmony with such facilities.

8. Neighborhood Residential Zone: This zone is designated to provide daily shopping facilities for the neighborhood residents. In addition to residential and shop buildings, small factory buildings are permitted.

9. Commercial Zone: Banks, cinemas, restaurants, and departmental stores are constructed in this zone. Residential buildings and small factory buildings are also permitted.

10. Quasi Industrial Zone: This zone is mainly occupied by light industrial facilities and service facilities. Almost all types of factories are permitted excepting those which are considered to considerably worsen the environment.

11. Industrial Zone: any type of factory can be built in this zone. While residential and shop buildings can be constructed, school, hospital and hotel buildings are not permitted.

12. Exclusively Industrial Zone: this zone is designated for factories. While all types of factory buildings are permitted, residential, shop, school, hospital and hotel buildings cannot be constructed.

\section{RESULT AND DISCUSSIONS}

From the above comparative study of planning in Maharashtra and Japan, inferences based on the similarities and differences in the planning approach adopted, are drawn.
- Land Acts are the various legal provisions for planning India, whereas, The City Planning Act and others provide legal base for planning in Japan.

- No specific planning standards are observed in Japanese Planning though there are Japanese Building Code, divided into Single Code for individual building and Group code for Building and city, surrounding area.

- The land use zoning is based on Density. The technique of Area Division System for planning the usage of land in Japan as Urbanization Promotion Areas and Urbanization Control Areas are to be considered in the haphazardly growing urban areas in India.

- The transportation is given prime importance in Japanese planning.

- In Japan, public Participation is preferred in the planning process right from the initial stages of planning.

- The provision of the City Planning Act for conducting surveys approximately in 5 years keeps the planning process updated and the Plans head the city towards sustainable development.

- In the local context of Maharashtra, the implementation of the Development plan majorly seen as at very low rate. Also the concepts of various zones can be crosschecked in context with Japanese Zone Planning.

Significant inferences are presented here in Table 1.

Table 1: Comparative study of Planning

\begin{tabular}{|c|c|c|c|}
\hline $\begin{array}{l}\text { Sr. } \\
\text { No. }\end{array}$ & Particular & $\begin{array}{l}\text { Planning in } \\
\text { Maharashtra }\end{array}$ & $\begin{array}{l}\text { Planning in } \\
\text { Japan }\end{array}$ \\
\hline 1 & $\begin{array}{l}\text { Basic Concept } \\
\text { of Planning : } \\
\text { In concern with } \\
\text { planning } \\
\text { scenario } \\
\text { Maharashtra } \\
\text { State and Japan, } \\
\text { the } \\
\text { basic concept of } \\
\text { planning } \\
\text { remains majorly } \\
\text { the same. }\end{array}$ & 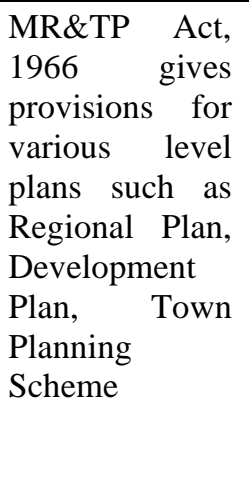 & $\begin{array}{l}\text { Plans at various } \\
\text { levels: National } \\
\text { Planning, } \\
\text { Prefectural } \\
\text { Planning and } \\
\text { Municipal } \\
\text { Planning, City } \\
\text { Plans and } \\
\text { District Plans }\end{array}$ \\
\hline 2 & Zoning: & $\begin{array}{l}\text { Zones:5 } \\
\text { Residential, } \\
\text { Commercial, } \\
\text { Industrial, } \\
\text { Agricultural } \\
\text { and } \\
\text { Recreational. }\end{array}$ & $\begin{array}{l}\text { Zones : } 12 \\
\text { Major zones are } \\
\text { Residential, } \\
\text { Commercial } \\
\text { and Industrial, } \\
\text { further these are } \\
\text { divided in sub } \\
\text { zones. }\end{array}$ \\
\hline 3 & $\begin{array}{l}\text { Involvement of } \\
\text { Public: }\end{array}$ & $\begin{array}{l}\text { More } \\
\text { qualitative } \\
\text { involvement at } \\
\text { all stages is } \\
\text { essential. }\end{array}$ & $\begin{array}{l}\text { Active } \\
\text { involvement of } \\
\text { public since } \\
\text { planning stage. }\end{array}$ \\
\hline 4 & $\begin{array}{l}\text { Neighborhood } \\
\text { Planning }\end{array}$ & $\begin{array}{l}\text { Largely } \\
\text { ignored. }\end{array}$ & $\begin{array}{l}\text { Neighborhood } \\
\text { residential zone } \\
\text { is considered. }\end{array}$ \\
\hline
\end{tabular}




\section{Zoning Strategies for Urban Land Use Planning}

\section{CONCLUSION}

Detailed study of urban planning for Maharashtra and Japan has been carried out. The important aspect in Japanese Urban Planning is public participation preferred in the planning process right from the initial stages of planning. Also the neighborhood planning aspect needs to be considered in context of Maharashtra advance planning. The urban land use planning/ zoning system of Japan can be considered as guideline and a multi-criteria framework can be developed for advance planning of Maharashtra.

\section{ACKNOWLEDGEMENT}

Authors would like to thank the Government of Maharashtra and Government of Japan for joint study tour.

\section{REFERENCES}

1. Census of India 2011

2. Kiranmayi Raparthi, “Assessing Smart-Growth Strategies in Indian Cities:

Grounded Theory Approach to Planning Practice”, J. Urban Plann. Dev., ASCE, 141(4), 2004, pp. 05014031-1-10.

3. Hosseini, A., Pourahmad, A., and Pajoohan, M. "Assessment of Institutions in Sustainable Urban-Management Effects on Sustainable Development of Tehran: Learning from a Developing Country." $J$. Urban Plann. Dev. , (ASCE), 2015, pp. 05015009-1-14.

4. Yinghuan Feng, Rui Li and Liu Zeng "The Identification and Prioritization of Optimal Logistics Nodes Planning of Yanting County". 2015. pp. 795-802.

5. Fengjun Yin, Mao Ye, Xiucheng Guo and Miao Yu "Optimizing Average Spacing of Arterial Road Networks for New Towns in Large Cities". 2014: pp. 3205-3216.

6. Wanhong Wu, Shoujian Zhang and Manman Shi "Research on the Requirement Engineering Analysis of the Village and Town Construction Standard System". 2013, pp. 121-130.

7. Yikun Su, Guangmei Fan ,Haiquan Fu, Yu Liu and Shijing Yang "Study of Configuration and Use of Public Facilities in Villages and Towns against New-Type Urbanization Background”. 2013, pp. 1326-1333.

8. Deyong Yu, Yuan Jiang, Muyi Kang, Yuhong Tian and Jin Duan, "Integrated Urban Land-Use Planning Based on Improving Ecosystem Service: Panyu Case, in a Typical Developed Area of China.” J. Urban Plann. Dev., 10.1061/(ASCE), 2011, pp. 448-458.

9. Jianjun Wang, Xiangru Du, Airong Qu and Juanli Dai "Research on Planning Methods of Developed Small-Town Traffic System Based on "Important Degree-Traffic Location"”'. ICCTP 2011, pp. 267-274.

10. M. S. Mir, K. V. Krishna Rao and J. D. Hunt, "Space Development Modeling of Urban Regions in Developing Countries." J. Urban Plann. Dev., 10.1061/(ASCE)0733-9488, 2010, 136:1(75), pp. 75-85.

11. Ryosuke Ando, Keiichi Higuchi, Yasuhiro Mimura, "Data analysis on traffic accident and urban crime: A case study in Toyota City", International Journal of Transportation Science and Technology, Vol. 7 (2018), pp. 103-113.

\section{AUTHORS PROFILE}

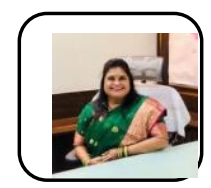

Pratibha Bhadhane, PhD Research Scholar, Civil Engineering, Dr. D. Y. Patil Institute of Technology, Pimpri, Pune, India.

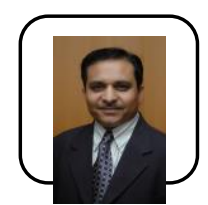

Dr. R.K.Jain, Principal, RSCOE, Tathwade, Pune, India He has vast academic and research experience. His field of expertise is Town Planning, Transportation and Geotechnical Engineering. He is a recognized research guide of SPPU.

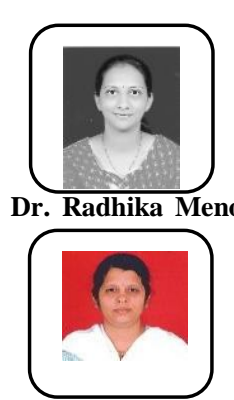

Dr. Deepa A. Joshi, Professor in Civil Engineering, Dr. D. Y. Patil Institute of Technology, Pimpri, Pune, India She has 17 years of experience in teaching. She is a recognized research guide of SPPU.

Dr. Radhika Menon, Professor, Dr. D. Y. Patil Institute of Technology, Pimpri, Pune, India. She has 20 plus years of academic experience, for the graduate and post graduate programmes. She is a recognized research guide of SPPU. 